\title{
Capsule Commentary on Bremmer et. al., Impact of Procalcitonin Guidance on Management of Adults Hospitalized with Chronic Obstructive Pulmonary Disease Exacerbations
}

\author{
Alexander G. Mathioudakis, MD, MRCP(UK) \\ Division of Infection, Immunity and Respiratory Medicine, The University of Manchester, Manchester, UK.
}

J Gen Intern Med 33(5):749

DOI: $10.1007 / \mathrm{s} 11606-018-4341-\mathrm{x}$

(c) The Author(s) 2018. This article is an open access publication

$\mathrm{R}$ ecent data reveal an alarming $50 \%$ increase in mean antimicrobial resistance within the last decade, across the OECD member countries. ${ }^{1}$ Moreover, the results of extensive campaigns against inappropriate antibiotic prescribing are only modest, ${ }^{2}$ emphasizing the need for alternative, effective stewardship methods. Serum procalcitonin, being able to differentiate bacterial versus viral infections or non-specific inflammation, is increasingly and successfully used to guide the initiation and/or discontinuation of antibiotics from primary to intensive care settings. ${ }^{3}$

Safe antibiotic avoidance in COPD exacerbations is of utmost importance: they are prevalent, responsible for $>10 \%$ of all hospital admissions ${ }^{4}$; and while $<50 \%$ are attributed to bacterial infections, patients frequently receive unneeded antibiotics, while their airways are colonised by bacteria that progressively become less sensitive to antibiotics. ${ }^{4}$ The efficacy and safety of procalcitonin to guide antibiotic administration in COPD exacerbations is supported by a meta-analysis of eight open-labelled clinical trials, which however highlights the methodological limitations and small overall population of the included studies. ${ }^{3}$

Bremmer and colleagues, in a retrospective pre-/post-intervention study assessed the safety and efficacy of the implementation of procalcitonin guidance for antibiotic administration for COPD exacerbations in the real world. ${ }^{5}$ Use of procalcitonin was clearly associated with a decrease in overall antibiotic exposure, without any safety signals. Interestingly, it was also correlated with decreased hospitalisation duration and, consequently, cost savings. That is consistent with previous results ${ }^{3}$ and could be attributed to an earlier discharge of patients when bacterial infection is excluded. However, the study is limited by its small study population $(n=305)$ and, possibly, selection bias, as only patients who had their procalcitonin measured were included in the postintervention group and clinicians might have omitted procalcitonin in severe presentations, where they would administer antibiotics anyway.
Another important, consistent observation was the relatively limited adherence to procalcitonin guidance, which probably reflects the limited confidence of clinicians on its safety. Indeed, few trials have tested compulsory adherence to procalcitonin guidance for antibiotic administration and none of them assessed COPD exacerbations. Therefore, the conduction of appropriately designed, adequately powered, confirmatory, pragmatic trials is urgently required to allow the introduction of procalcitonin guidance in clinical practice.

Corresponding Author: Alexander G. Mathioudakis, MD, MRCP(UK); Division of Infection, Immunity and Respiratory Medicine The University of Manchester, Manchester, UK (e-mail: Alexander. Mathioudakis@Manchester.ac.uk).

\section{Compliance with Ethical Standards:}

Conflict of Interest: The author declares that he does not have a conflict of interest.

Open Access This article is distributed under the terms of the Creative Commons Attribution 4.0 International License (http:// creativecommons.org/licenses/by/4.0/), which permits unrestricted use, distribution, and reproduction in any medium, provided you give appropriate credit to the original author(s) and the source, provide a link to the Creative Commons license, and indicate if changes were made.

\section{REFERENCES}

1. Policy insights: Antimicrobial Resisatance. OECD 2016. Available from: http://www.oecd.org/health/health-systems/AMR-Policy-Insights-November2016.pdf.

2. Davey P, Marwick CA, Scott CL, Charani E, McNeil K, Brown E, Gould IM, Ramsay CR, Michie S. Interventions to improve antibiotic prescribing practices for hospital inpatients. Cochrane Database Syst Rev. 2017;2:CD003543.

3. Mathioudakis AG, Chatzimavridou-Grigoriadou V, Corlateanu A, Vestbo J. Procalcitonin to guide antibiotic administration in COPD exacerbations: a meta-analysis. Eur Respir Rev. 2017;26(143).

4. Wedzicha JA, Seemungal TA. COPD exacerbations: defining their cause and prevention. Lancet. 2007;370(9589):786-96.

5. Bremmer DN, DiSilvio BE, Hammer C, Beg M, Vishwanathan S, Speredelozzi D, Moffa MA, Hu K, Abdulmassih R, Makadia JT, Sandhu R, Naddour M, Chan-Tompkins NH, Trienski TL, Watson C, Obringer TJ, Kuzyck J, Walsh TL (2018) Impact of procalcitonin guidance on management of adults hospitalized with chronic obstructive pulmonary disease exacerbations. J Gen Intern Med. https://doi.org/10.1007/ s11606-018-4312-2 